\title{
AUDIOTEXTOS CIENTÍFICOS PARA TODOS: estudos teórico-metodológicos em direitos humanos e inovação
}

\author{
Jeniffer Alves Cuty (UFRGS, jcuty@ufrgs.br) \\ Daniela Mei Lipp Nissinen (UFRGS, danielamei97@gmail.com) \\ Osmar Weyh (UFRGS, osmarweyh@gmail.com)
}

\begin{abstract}
RESUMO
Este artigo parte da experiência de pesquisa com audiotextos científicos para uso acadêmico, os quais foram produzidos no âmbito do Projeto de Extensão "Desenvolvimento de Objetos de Aprendizagem para Pessoas com Deficiência na FABICO, UFRGS, 2018”. O referido Projeto perpassou atividades do Grupo de Pesquisa Leitura, Informação e Acessibilidade, da Faculdade de Biblioteconomia e Comunicação da Universidade Federal do Rio Grande do Sul. Repensou a morfologia e o conteúdo de textos científicos, conseguindo identificar dificuldades de compreensão teórico-conceitual de estudantes de graduação, assim como barreiras efetivas ou simbólicas de escrita. Foi possível, no decorrer de um ano de projeto, executar a metodologia utilizada por locutores de textos em áudio, de modo a compreender especificidades da gravação desse tipo de texto. Apresenta também atenção com Direitos Autorais e gravações de voz a todo o tipo de público, Pessoas com Deficiência visual ou sem limitação, universalizando o acesso à informação. Como referencial teórico trabalhamos com a produção dos autores Cardoso, Cuty, Estabel, Fisher, Moro, além de Neves e Tojal. Discorremos sobre estudos textuais, panorama da deficiência no Brasil e desafios dos audiotextos e das tecnologias em bibliotecas e museus.
\end{abstract}

Palavras-chave: Audiotexto. Direitos Humanos. Acessibilidade. Inovação. Artigos Científicos

\begin{abstract}
This article is part of the research experiment with scientific audiotexts for academic use, which were produced under the Extension Project "Development of Learning Objects for People with Disabilities at FABICO, UFRGS, 2018". This project was part of the activities of the Reading, Information and Accessibility Research Group of the Faculty of Library and Communication of the Federal University of Rio Grande do Sul. It rethought the morphology and content of scientific texts and managed to identify difficulties of theoretical-conceptual understanding of students
\end{abstract}


as well as effective or symbolic barriers to writing. It was possible, during a Project year, to execute the methodology used by speakers of audio texts, in order to understand the specifics of the recording of this type of text. It also provides attention with Copyrights and voice recordings to all types of people, People with Visual Disabilities or without limitation, universalizing access to information. As a theoretical reference, we work with the authors Cardoso, Cuty, Estabel, Fisher, Moro, Neves and Tojal. We deal with textual studies, the panorama of disability in Brazil, and the challenges of audiotext and library and museum Technologies.

Keywords: Audiotext. Human rights. Accessibility. Innovation. Scientific articles

\title{
INTRODUÇÃO
}

\begin{abstract}
Hoje me pergunto por que amo a literatura, a resposta que me vem espontaneamente à cabeça é: porque ela me ajuda a viver. [...] Longe de ser um simples entretenimento, uma distração reservada às pessoas educadas, ela me permite que cada um responda melhor à sua vocação de ser humano.
\end{abstract}

Tzvetan Todorov

A leitura nos torna humanos e preparados para todo tipo de aprendizado. Colocamo-nos no mundo, entre outras formas, por meio da leitura, de modo críticoreflexivo e, sobretudo, criativo, o que nos possibilita identificar novos conceitos, repensar metodologias de trabalho e avançar como sociedade humanizada. No âmbito dos Direitos Humanos é a leitura (ou a escuta de textos literários ou científicos) que nos asseguram narratividade ou, como bem nos ensinam Ricoeur (1993) e Butler (2017), narrarmo-nos para estes outros que nos cercam e que buscam interação. Sem capacidade narrativa, corremos o risco do plágio, da perda de filtro ético e da incompreensão de quem nos cerca sobre quem somos. É a narrativa que humaniza o tempo, configura-o, como nos ensina Ricoeur (1993), e ela pode se apresentar de modo ficcional ou não, construindo cosmovisões ou revelando interpretações sociais e coletivas.

Da mesma forma que o texto lido se dispõe a nossa memória, por meio de relações cognitivas e afetivas, o texto em áudio em sua topografia, formada por entonações e pausas/silêncios, remete-nos a experiências como a escuta de programas de rádio, podcasts e radionovelas. Audiotextos e audiolivros se colocam como universos a serem melhor explorados e difundidos na formação acadêmica, pois incluem deficientes visuais, pessoas com autismo e estudantes ou professores que convivem com deslocamentos RENOTE 
longos, durante sua jornada diária, podendo, por meio desse recurso tecnológico, estudar textos de aula no carro, no ônibus ou a pé.

No âmbito do patrimônio e da Museologia, dispomos dos tradicionais audioguias em museus, os quais nos dão acesso a informações sobre as obras, os artistas que as produziram e o contexto de produção. A audiodescrição, por sua vez, assegura à Pessoa com Deficiência (PcD) acesso à compreensão do espaço expográfico e das imagens que ali se encontram, fixas ou em movimento. A audioleitura pode ser um recurso para versões disponíveis na internet de textos produzidos pelos curadores ou pelo educativo dos museus, promovendo amplo acesso. Segundo Cuty (2012, p. 18), “a preservação do patrimônio cultural carrega, na sua essência, um diálogo estreito com a filosofia dos direitos culturais, pois ambas as manifestações têm por finalidade a vinculação dos indivíduos com seus ambientes culturais”.

Ainda no contexto museológico, a pesquisadora portuguesa Neves (2010) nos provoca a pensar em museus como lugares para experiências multissensoriais, respeitando a singularidade de cada participante/visitante do museu. “Estar preparado para receber todos poderá significar pensar, antecipadamente, em cada um, criando motivos para que cada visitante, na sua individualidade, encontre razões para querer voltar àquele espaço.” (p.183).

Em bibliotecas, a necessidade da oferta de audiotextos e audiolivros é mais evidente e os usuários com deficiência demandam livros específicos nesses espaços. No caso de bibliotecas universitárias, a possibilidade de oferecimento de artigos ou obras de domínio público, no formato em áudio, pode representar a construção do acesso à audioleitura e dos estudos adaptados ao tempo contemporâneo de deslocamentos maiores pelas cidades conurbadas e da redução de práticas imersivas de leitura.

Este artigo aborda, portanto, a reflexão teórico-metodológica feita no projeto sobre audiotextos que realizamos na Fabico/UFRGS, tomando como base conceitual o debate sobre leitura e hermenêutica do que nos cerca, o patrimônio cultural e documental, acessibilidade e exclusão/inclusão. Não perdemos de vista nosso compromisso científico e ético com a reflexão sobre Direitos Humanos, a qual permeia nossas questões epistemológicas e pedagógicas. A escrita deste texto foi feita por uma docente doutora da Faculdade de Biblioteconomia e Comunicação da UFRGS e por dois estudantes, sendo eles oriundos dos cursos de Museologia e Biblioteconomia desta Universidade. 


\section{CONSTRUÇÃO TEÓRICO-METODOLÓGICA}

A locução textual se aproxima da lógica do teatro, pois ela depende de compreensão e apropriação do texto, em sua forma e conteúdo, por parte de quem o narra. Esta é uma dificuldade cotidiana no ambiente acadêmico que se manifesta, logo em seguida, na necessidade de escrita. Muitos acadêmicos não tem, no seu contidiano, a leitura de livros, na sua integralidade; buscam a leitura, mas não conseguem narrar sobre o que leram. Dispersão, dificuldade de identificação de pontos para ênfase, dificuldade de compreensão conceitual estão na lista de barreiras cognitivas encontradas em sala de aula. Além disso, é grande o número de pessoas que sabem ler e não compreendem o que leem.

Por outro lado, a proximidade com a literatura, em seus distintos gêneros, auxiliaria sobremaneira aos graduandos e pós-graduandos na atividade de ler (ou audioler) estudando. Parece insuficiente ao docente universitário explorar a assimilação morfológica de um texto com seus alunos, identificar a trajetória do autor, destacando objetivos no texto analisado, para, por fim, atingir a ênfase nos conceitos e nas categorias propostas para estudo. É necessário adentrar nos estudos de lógica dos argumentos, para obter avanços na hermenêutica textual e no almejado pensamento crítico e autônomo.

Fisher (2008), autor inglês de lógica, contribui para esta reflexão. Para o autor, a possibilidade para o desenvolvimento de um pensamento imaginativo e inventivo é saber deter-se na avaliação dos argumentos de um texto apresentado, com um aparato intelectual simples, o qual não requer acionar especialistas para uma resolução. A lógica é um campo filosófico que nos possibilita identificar em um texto ou em um discurso, conclusões e razões apresentadas ao seu favor, ou seja, o "leitor deverá dizer primeiramente se [...] (está diante de) um argumento (se contém um raciocínio a favor de uma conclusão)” (FISHER, 2008, p.8). Diante dos argumentos, o estudante deve relacionar à sua conclusão e quais razões estão oferecidas a favor dessa conclusão. O que pode parecer um exercício simples de raciocínio é o primeiro passo de compreensão de um texto, na sua estrutura argumentativa e conclusiva, possibilitando, assim, ao acadêmico, redigir os seus textos de forma lógica.

No âmbito das técnicas para a locução devemos estar atentos para o processo de estudo e compreensão do texto, mas também para cuidados com o sistema vocal do locutor. As recomendações perpassam a alimentação leve até os exercícios de relaxamento da face, de modo a obter um desempenho mais equilibrado durante o RENOTE 
trabalho de gravação dos textos. No texto científico, diferentemente do texto literário, a prosódia - ou a entonação de palavras e frases - ganha outra dimensão, sendo utilizada com menor frequência e com o cuidado para não descaracterizar o texto. Pausas e gravação com vozes distintas, uma feminina e outra masculina, podem ser boas estratégias para obtenção de áudios menos monótonos e com melhor compreensão de citações e indicação de notas. Cabe ainda destacar que o locutor, ao cometer equívocos, pode, imediatamente, avisar ao técnico de som do estúdio, por meio de uma frase como “vou refazer” e, em seguida, regravar o áudio. Essa estratégia facilita a edição final dos audiotextos. No contexto do projeto que realizamos, tivemos a oportunidade de gravar os textos de domínio público, selecionados para a pesquisa, no estúdio de rádio da faculdade, o qual possui estrutura de equipamentos e isolamento acústicos adequados.

No que tange ao debate sobre Direitos Humanos e Acessibilidade, cabe vislumbrarmos o panorama nacional. No Brasil, o Censo do IBGE, de 2016, aponta que 24\% da população convive com algum tipo de deficiência. Para além das barreiras sociais, físicas e comunicacionais, este grupo enfrenta também situações de preconceito e estigma enraizadas e por muitos silenciadas nas relações cotidianas. No entanto, conforme a antropóloga Diniz (2007), o corpo com deficiência representa a expressão da diversidade humana. Partindo desse pressuposto, e levando em conta as diversas políticas existentes em diferentes países que visam assegurar os direitos previstos em legislações, cabe a todos a constante reflexão sobre o quanto isso de fato se aplica e se reconhece como condição de existência e autonomia para muitos.

São inúmeras as barreiras atitudinais que sustentam atitudes preconceituosas e discriminatórias e também impedem o pleno acesso das Pessoas com Deficiência (PcD). Estas podem ser tanto intencionais ou não, e o desafio constante é a sensibilização e o conhecimento. Faz-se necessário assegurar o espaço de comunicação e escuta em que todos possam livremente se expressar, vivenciar e partilhar das mesmas oportunidades no convívio social, mesmo que através de diferentes formatos. Primordialmente, a partir da comunicação, seja ela oral, escrita ou gestual, é possível exercer a liberdade de expressão, bem como garantir outros direitos assegurados a todos. A partir dela é que se pode estabelecer um núcleo de convivência e integração indispensável para a construção de uma sociedade mais justa e inclusiva (IBRAM, 2016). Assim, se torna imprescindível democratizar o acesso aos conteúdos informacionais que sustentam a construção de posicionamentos e criticidade aos cidadãos, uma vez que os vários tipos de linguagem podem não abranger os diferentes níveis e possibilidades de apreensão de cada um. Para RENOTE 
tanto, a Convenção Internacional dos Direitos da Pessoa com Deficiência, ratificada pelo Brasil em 2008, prevê a elaboração e a disponibilização de alternativas, por meio da Acessibilidade Comunicacional, que assegurem o direito à informação, à cultura e ao lazer. O direito constitucional e os direitos humanos são passíveis de serem alcançados ao passo que são superadas as barreiras comunicacionais por meio de ações e recursos de caráter interpessoal, tais como:

a língua de sinais, linguagem corporal, linguagem gestual, comunicação face-a-face; sob a forma escrita, como jornais, revistas, livros, incluindo texto em braille, com letras ampliadas para quem tem baixa visão; notebook, tecnologias assistivas, como a comunicação alternativa; e comunicação virtual, no campo da acessibilidade digital. (IBRAM, 2016).

A realidade brasileira aponta para uma legislação densa, contando com a garantia do desempenho de direitos sociais e individuais prevista na Constituição de 1988, a primeira lei específica em defesa da acessibilidade, ou seja, a Lei $n^{0} 10098 / 2000$, que prevê autonomia e oportunidades para todos. Além dessa norma, dispomos do Decreto 5.296/2004 que assegura o acesso pleno à comunicação e à informação, bem como atendimento prioritário e adequação de projetos arquitetônicos e urbanísticos e o Estatuto da Pessoa com Deficiência (2015), o qual trata dos direitos fundamentais das Pessoas com Deficiência, reforçando a garantia do acesso à informação e à comunicação e aborda as punições existentes a quem descumprir as indicações. A previsão de punições não assegura acesso ou direitos, ao contrário, cria uma falsa ideia de adesão de empresas, instituições e indivíduos aos princípios de acessibilidade e direitos humanos. Leis e normas demandam fiscalização e, não prescindem, felizmente, de educação para a sua observância.

O Brasil apresenta profícuas iniciativas pontuais que disponibilizam a informação em diversos níveis de elaboração, promovendo a literacia. Apresenta-se, no entanto, um crescimento nas discussões em acessibilidade, com destaque para a área cultural, visto que é recente a conquista de direitos, escuta e participação das Pessoas com Deficiência nos mais variados contextos.

No âmbito das bibliotecas, por sua vez, e nos períodos que as antecederam, a figura do contador de histórias assumiu um papel primordial, fazendo o elo de ligação entre o narrador e ouvinte. A voz está relacionada à pessoa que a narra, ou seja, ao personagem narrador. Walter Benjamin (1993) já nos alertara sobre o conceito de 
experiência condensado nas narrações desses sujeitos que se descaracterizaram no trajeto da humanidade. Em Experiência e Pobreza (1993), Benjamin nos fala sobre um pai agricultor que, no seu leito de morte, alerta seus filhos sobre um tesouro na plantação da família. Os filhos, por sua vez, resistem a aceitar que o tesouro está na observação sensível da troca de estações do ano e em suas especificidades, as quais possibilitarão um plantio adequado e farto. Em contraponto a esta densidade filosófica do trabalho benjaminiano, os autores Souza, Celva e Helvadjan (2010), pontuam que:

Na linha do tempo, o contador de histórias é milenar. Está ligado aos contos de fada, às caravanas, às fábulas orientais, à curiosidade dos que esperavam por esses momentos de companhia, de contato com um mensageiro que lhes trazia novidades, que lhes descortinava 0 desconhecido, sobretudo que lhes alimentava o imaginário e o desejo de habitar outros lugares, de conviver e de compartilhar com outros seres, de coabitar o desconhecido.

No desenvolvimento da escrita, a figura do narrador acaba se diluindo. As histórias passam a ser compartilhadas por suportes físicos e a pessoa passa a ser capaz de decifrar os símbolos nele contidos, torna-se um narrador quando se dispõe a reverberar sua apropriação dos textos lidos.

A escrita e até os suportes informacionais se transformaram de modo mais acentuado a partir da segunda metade do século XX. Há quem acreditava, no início da adaptação com as tecnologias da informação - no âmbito de escolas, universidades e empresas e, sobretudo no cotidiano -, de que os livros e as bibliotecas seriam substituídos por ebooks e repositórios virtuais. Os bibliotecários e os chamados usuários, no entanto, seguem interagindo nas bibliotecas, mesmo que muitos deles sejam nativos digitais. Já nasceram nessa era digital (GUIMARÃES, 2010) e são acostumados com tecnologias, pois convivem num contexto social cada vez mais virtualizado. Segundo reportagem de Borrull (2019) para a British Broadcasting Corporation (BBC), já convivemos com uma nova geração, os alfas. Segundo o autor, esta seria a geração com maior dificuldade para assimilar um mundo analógico, longe das facilidades do virtual.

Mas nenhuma geração até agora se compara à geração alfa - formada pelos filhos dos millennials - neste aspecto. Ela será a primeira geração para qual muitos aspectos do mundo analógico parecem bem distantes de sua realidade. Nellis explica que, enquanto as outras gerações ainda aprendem a se adaptar ao mundo digital, as crianças alfa representam a "primeira geração digital". (BORRULL, 2019).

Ainda segundo o autor, enquanto as outras gerações ainda aprendem a se adaptar 
ao mundo digital, as crianças alfa representam a primeira geração digital. Tudo para eles corre mais rápido, instantâneo, as limitações da distância são superadas pela informação em tempo real em qualquer parte do mundo, bem como as comunicações nos diferentes idiomas, suportes informacionais ou em qualquer hora do dia. Há uma possibilidade já vivenciada de estudantes com dificuldade de concentração e leitura, oriundos dessa geração que transita com serenidade pelas tecnologias digitais.

\section{RESULTADOS E DISCUSSÃO}

Refletimos sobre a acessibilidade em instituições educacionais e, portanto, como estas desempenham ou devem desempenhar o diálogo, a interação e a experimentação como oportunidade para a plena fruição cultural. No caso dos audiotextos e audiolivros, e como importante ponto de partida para sustentar essas relações, objetivamos assegurar a ampliação da percepção multissensorial de conteúdos acadêmicos. Segundo Tojal (2014), esta dimensão amplia o acesso do público leitor aos mais diversos canais de experimentação e exploração, permitindo, dentro das características e das especificidades de cada público, que ele possa, com todo o seu potencial, apropriar-se do objeto cultural. Segundo Tojal (2014), esta dimensão amplia o acesso do público leitor aos mais diversos canais de experimentação e exploração, permitindo-lhe, dentro das características e das especificidades de cada público, apropriar-se do objeto cultural com todo o seu potencial. Ainda, para a mesma autora, esses canais podem ser estimulados por meio de recursos midiáticos, especialmente concebidos para facilitar a percepção do objeto cultural por parte do público fruidor, fator esse fundamental para a compreensão e o significado desse objeto (TOJAL, 2014).

A disponibilização do texto para formato de áudio, de maneira adaptada, coerente e seguindo recomendações para a sua plena compreensão, possibilita à PcD o acesso aos conteúdos textuais veiculados em sala de aula. Promove, assim, sua autonomia para a apropriação de conhecimentos e a participação ativa em debates e projetos suscitados tanto na esfera acadêmica, como nos demais setores da sociedade. Conforme Tojal (2014),

as concepções apresentadas pelos métodos de percepção 
multissensorial, aplicadas tanto na educação formal (instituições educativas) como na educação não-formal (instituições socioculturais), reforçam as teses sobre as mudanças de paradigma envolvendo o ensino e a aprendizagem na atualidade, evidenciando a necessidade de mudanças estruturais e pedagógicas que respeitem, antes de tudo, a inclusão e participação mais efetiva de todos os seres humanos em nossa sociedade. (p.29).

Debates em torno da acessibilidade trazem à tona a problemática dos direitos e da justiça social nos mais sutis níveis da relação social. Demonstra a urgência em reconhecêla como possibilidade e condição de alcance para a utilização dos dispositivos educacionais e culturais, seja no ato de se deslocar em seus espaços e usufruir de seus elementos, seja na participação social e inclusão em suas programações. Conforme a publicação Subsídios para a elaboração de Planos Museológicos (IBRAM, 2016), vale lembrar que:

o art. 27, da Declaração Universal dos Direitos Humanos (DUDH, 1948) diz que: "Todo ser humano tem o direito de participar livremente na vida cultural da comunidade, de fruir das artes e de participar do progresso científico e de seus benefícios". Para os fins de acessibilidade, conforme $\mathrm{o}$ art. $8^{\circ}$ do Decreto $\mathrm{n}^{\circ} 5.296$ de 2 de dezembro de 2004, que trata do tema, considera-se: I - acessibilidade: condição para utilização, com segurança e autonomia, total ou assistida, dos espaços, mobiliários e equipamentos urbanos, das edificações, dos serviços de transporte e dos dispositivos, sistemas e meios de comunicação e informação, por pessoa portadora de deficiência ou com mobilidade reduzida. (IBRAM, 2016)

Cabe aos diferentes espaços e às iniciativas, sobretudo de caráter público, serem exemplos de microlocais que possibilitam o acesso universal para, consequentemente, estimularem em um contexto maior as perspectivas da sociedade civil e de poderes públicos para uma frequente discussão acerca de possíveis soluções e intervenções na área de acessibilidade. Ressalta-se a importância de prever a participação ativa das Pessoas com Deficiência na estruturação de planos e recursos acessíveis com o intuito de escutar as demandas e os desafios que os grupos lidam em seu cotidiano e, assim, elaborar políticas em consonância com as realidades e especificidades de cada indivíduo. Também, a relevância de tornar ampla a difusão dos direitos e deveres inerentes às Pessoas com Deficiência a fim de sensibilizar primordialmente a sociedade a aprender e reconhecer as diferenças e singularidades de cada indivíduo. Isto torna possível a participação na fiscalização e reivindicação de espaços e iniciativas que promovam e permitam o acesso universal em suas atividades, bem como a capacitação de profissionais e pessoas envolvidas com PcD. Para Tojal (2014), a igualdade de direitos está 
intrinsecamente relacionada ao respeito pela diversidade coletiva ou individual. Segundo Vilaronga (2011, p. 6, apud BEZERRA; RAMOS, 2015, p.78):

O acesso à cultura e ao lazer, à informação e ao conhecimento, de forma, ao mesmo tempo, diferente e igualitária constitui uma das chaves do desenvolvimento humano e social. Diferente, porque é preciso assegurar a acessibilidade a todo e qualquer indivíduo, considerando suas formas de percepção e leitura de mundo; igualitária, porque todos devem ter acesso à cultura em igualdade de condições.

Que os percursos culturais e educacionais, bem como as demais dimensões sociais possam cada vez mais ser repensados e reinventados de modo a contemplar não só o direito de ir e vir e o pleno acesso das Pessoas com Deficiência, mas também a relação com uma multissensorialidade capaz de estimular o potencial de uma autonomia sensível e gerar experiências enriquecedoras que reconheçam e incluam as múltiplas identidades.

\section{CONCLUSÕES}

Entendemos que não há como iniciar e conduzir um projeto de pesquisa ou de extensão sem uma densa apropriação conceitual. Os conceitos servem de baliza teórica, muitas vezes limitando o percurso do pesquisador. Estes limites, no entanto, são necessários, pois dispomos de objetivos, um problema e prazos a cumprir. Por outro lado, a metodologia nos amplia sobremaneira as possibilidades reflexivas e criativas. Ela parte da nossa realidade social, mas se aplica, com as devidas adequações, a outros contextos. É a diversidade humana se manifestando no fazer científico, mesmo que ela, a diversidade, ainda seja vista com resistência ou seja, autoritariamente, invisibilizada, como se isso fosse possível.

O audiolivro e o audiotexto são formas diversas de promover a inclusão, de modo quase simples, como ação prática e aplicável de se utilizar as tecnologias de informação para o amplo acesso à cultura e à informação. Audiolivros assemelham-se muito aos antigos dispositivos de fitas K7 (Cassete). Atualmente a disponibilidade de dispositivos é maior, podendo ser ofertados em mídias físicas, virtuais ou na nuvem, como o caso de podcasts, adaptando a informação de acordo com o dispositivo utilizado e familiarizado 
pela pessoa. Em geral os livros falados ou audiolivros, são produzidos por Organizações Não-Governamentais (ONGs) ou organizações filantrópicas, aproveitando o recurso de Domínio Público ou a autorização do autor/editor para publicação em formato digital.

Para tornar indivíduos sujeitos atuantes e críticos na sociedade, professores, museólogos e bibliotecários, na perspectiva que nos dispusemos a refletir neste texto, devem buscar conhecer estratégias e recursos que, na compreensão dos direitos humanos, superem a exclusão. A exclusão é a primeira rocha que se coloca diante da diversidade e das necessidades humanas, bem como é a injustiça que se coloca, a priori, no mundo. Conhecer metodologias, transformá-las e adequá-las à realidade de grupos sociais, de instituições e de contextos humanos é um movimento político a ser, permanentemente, proposto por todo cidadão.

Ler, audioler e percorrer blogs, canais do Youtube, mídias sociais compõem o rol de atividades que nos cercam. Há quem ainda não tem acesso a elas, sabidamente. No entanto, a narração e a narrativa são inerentes ao ser humano. Mesmo não dispondo de acesso a esses recursos, os quais, como já nos alertara nos anos 1930 Benjamin, é a narração que carrega a densidade da memória. Se a narrativa configura o tempo, ainda é a narrativa literária, fílmica ou expositiva que nos possibilita repensar o humano. As mídias sociais nos possibilitam à interação imediata, no entanto, não são propostas como espaços de buscas de dados a longo prazo e, muito menos, de reflexão mnemônica. Assim, elas não contemplam os princípios de memória, como artigos, livros, audiotextos e audiolivros contemplam, desde a sua concepção.

\section{REFERÊNCIAS}

BARBOSA, Rafael de Oliveira. Tipos de Letramento e Audioleitura: Considerações sobre Competências Cognitivas e Modelos de Negócio Emergentes. In: Congresso Brasileiro de Ciências da Comunicação, 38., 2015, Rio de Janeiro. Anais. Rio de Janeiro: Intercom, 2015. p. 1 - 11. Disponível em: https://www.ufrgs.br/leadproducaoeditorial/wp-content/uploads/2015/08/Tipos-de-Letramento-e-

Audioleitura.pdf. Acesso em: 23 jun. 2019.

BEnjamin, Walter. Magia e Técnica, Arte e Política. Ensaios sobre Literatura e História da Cultura. São Paulo: Brasiliense, 1993.

BEZERRA, Fernanda Antônia; RAMOS, Joranaide Alves. A Importância do Áudiolivro para o Deficiente Visual no Estudo de Literatura. Anais do Festival Literário de 
Paulo Afonso - FLIPA, 2015. Faculdade Sete de Setembro - Paulo Afonso, Bahia.

BORRULL, Alba Solé. O que É a Geração Alfa, a 1a a ser 100\% digital. 2019. Disponível em: https://www.bbc.com/portuguese/geral48438661 ?ocid=socialflow_facebook\&fbclid=IwAR0SX4T65V7-f64l0xl4y4oC3GPKTN-ri2aqzqIn9LdJI7kgiSQjJd902k. Acesso em: 02 jun. 2019.

BRASIL. Decreto $\mathbf{N}^{\mathbf{0}} \mathbf{5 . 2 9 6}$ de 2 de dezembro de 2004, que regulamenta as Leis nos 10.048 , de 8 de novembro de 2000 , que dá prioridade de atendimento às pessoas que especifica, e 10.098, de 19 de dezembro de 2000, que estabelece normas gerais e critérios básicos para a promoção da acessibilidade das pessoas portadoras de deficiência ou com mobilidade reduzida, e dá outras providências. Disponível em: http://www.planalto.gov.br/ccivil_03/_ato2004- 2006/2004/decreto/d5296.htm. Acesso em: 20 jun. de 2019.

BRASIL. INSTITUTO BRASILEIRO DE GEOGRAFIA E ESTATÍSTICA. Censo IBGE de Pessoas com Deficiência (PCD). Disponível em: http://www.brasil.gov.br/economia-e-emprego/2016/09/cresce-numero-de-pessoas-comdeficiencia-no-mercado-de-trabalho-formal. Acesso em: 20 jun. de 2019.

BUTLER, Judith. Relatar a Si Mesmo: crítica da violência ética. Belo Horizonte: Autêntica, 2017.

CARDOSO, Eduardo; CUTY, Jeniffer. Acessibilidade em Ambientes Culturais. Porto Alegre: Marcavisual, 2012.

CUTY, Jeniffer. Revisando a dimensão conceitual e política da cultura de preservar cidades. In: FRANÇA, Maria Cristina; LOPES, Cicero Galeno e BERND, Zilá (org.). Patrimônios memoriais: identidades, práticas sociais e cibercultura. Série Memória e Patrimônio 2. Porto Alegre: Movimento; Canoas: Unilasalle, 2010. p. 126141.

DINIZ, Débora. O que é Deficiência? São Paulo: Brasiliense, 2007. (Coleção Primeiros Passos).

DOWBOR, Ladislau; SILVA, Hélio. (Org.). Propriedade Intelectual e Direito à Informação. São Paulo: EDUC, 2014.

ORGANIZAÇÃO DAS NAÇÕES UNIDAS. DUDH - DECLARAÇÃO UNIVERSAL DOS DIREITOS HUMANOS. Disponível em: https://nacoesunidas.org/wp-content/uploads/2018/10/DUDH.pdf. Acesso em: 20 jun. de 2019.

FARIAS, S. C. O audiolivro e sua contribuição no processo de disseminação de informações e na inclusão social. RDBCI: Revista Digital de Biblioteconomia e Ciência da Informação, v. 10, n. 2, p. 31-52, 10 jul. 2012. Disponível em: https://doi.org/10.20396/rdbci.v10i1.1895. Acesso em: 23 jun. 2019.

FISHER, Alec. A Lógica dos Verdadeiros Argumentos. São Paulo: Novo Conceito Editora, 2008. 
IBRAM. Subsídios para a elaboração de Planos Museológicos, 2016.112p. Disponível em: https:/www.museus.gov.br/wp-content/uploads/2017/06/Subs\%C3\%ADdios-paraa-elabora\%C3\%A7\%C3\%A3o-de-planos-museol\%C3\%B3gicos.pdf. Acesso em: 21 jun. 2019.

JOGANDO Às CEGAS. Saiba como Funciona o Processo de Produção de um Audiolivro. 2016. Disponível em: http://jogandoascegas.com.br/audiolivro/. Acesso em: 15 jun. 2019.

MENEZES, Nelijane C.; FRANKLIN, Sérgio. AUDIOLIVRO: uma importante contribuição tecnológica para os deficientes visuais; um estudo de caso no Setor Braille da Biblioteca Pública do Estado da Bahia. In: ENCONTRO NACIONAL DE ENSINO E PESQUISA EM INFORMAÇÃO, 8., 2008, Salvador. Anais. Salvador: UFBA, 2008. p. 1 - 15. Disponível em:

http://www.cinform2008.ici.ufba.br/layout/padrao/azul/cinform/Documentos/Co munica\%C3\%A7\%C3\%B5es/AUDIOLIVRO\%20uma\%20importante\%20contribui\%C 3\%A7\%C3\%A3o\%20tecnol\%C3\%B3gica\%20para\%20os\%20deficientes\%20visuais.... pdf. Acesso em: 15 jun. 2019.

MOMESSO, Maria Regina et al. (org.). Educar com Podcasts e Audiobooks. Porto Alegre: Cirkula, 2016.

NEVES, Josélia. COMUNICAÇÃO MULTI-SENSORIAL EM CONTEXTO MUSEOLÓGICO. Actas do I Seminário de Investigação em Museologia dos Países de Língua Portuguesa e Espanhola, 2010, Volume 2, p. 180-192.

NEVES, Josélia. Multi-sensory approaches to (audio) describing visual art. Mimeo, 2011.

RICOEUR, Paul. Tempo e Narrativa. Tomo I. Campinas: Papirus, 1993.

SOUZA, Maria Salete Daros de; CELVA, Rubia Aparecida; HELVADJIAN, Vanessa. Audiolivro: um suporte para a educação literária. Leitura: TEORIA \& PRÁTICA, Campinas, v. 28, n. 55, p.28-36, dez. 2010. Semestral. Disponível em: https://tp.emnuvens.com.br/ltp/article/view/69. Acesso em: 23 jun. 2019.

TODOROV, Tzvetan. A Literatura em Perigo. Rio de Janeiro: Difel, 2017.

TOJAL, Amanda Pinto da Fonseca. Comunicação museológica e ação educativa inclusiva. IN: CARDOSO, Eduardo e CUTY, Jeniffer (org.). Acessibilidade em Ambientes Culturais: relatos de experiências. Porto Alegre: Marcavisual, 2014, p. 1433. 